\title{
Third party anti-dumping: A tentative rationale
}

\author{
Martin Richardson \\ School of Economics, Faculty of Economics and Commerce, Australian National University, \\ Canberra ACT 0200, Australia
}

Received 12 February 2005; received in revised form 25 June 2005; accepted 1 October 2005

Available online 25 January 2006

\begin{abstract}
This paper considers the phenomenon of third party antidumping; that is, the ability of a firm to bring an $\mathrm{AD}$ case in a foreign country against third party dumpers. Recent experience in New Zealand is discussed and suggestions are offered as to why a country might wish to permit foreigners to demand that other foreigners increase prices in that country.
\end{abstract}

(C) 2005 Elsevier B.V. All rights reserved.

JEL classification: F12; F13; F15

Keywords: Anti-dumping; Third-party anti-dumping

\section{Introduction}

There are no producers of a product called "clear float glass"' in New Zealand (NZ) and there have been no producers of sheet glass in NZ since Pilkington (NZ) Ltd., a NZ subsidiary of the British multinational Pilkington PLC, closed its Whangarei plant in 1991. ${ }^{2}$ In 1997 an antidumping (AD) case was lodged with the NZ Secretary of Commerce alleging dumping of

E-mail address: martin.richardson@anu.edu.au.

1 The float process was invented by one Sir Alastair Pilkington in 1952 and makes glass for buildings and vehicles. Extremely hot molten glass is poured onto a pan of melted tin where it floats and spreads into a flat surface, the thickness of which can be adjusted by the speed at which the glass is drawn off the tin. Float plants are extremely capital intensive and have high minimum efficient scale. They are designed to operate continuously for over a decade and there are over 260 worldwide (source: www.pilkington.com).

2 The reasons given for the plant's closure were that it could not compete with imported glass (mainly from China) in the absence of tariff protection and that it was technologically outdated (National Business Review, 1991). The cost of converting the plant to a float plant was in the order of NZ\$70m and was not considered economic, given the limited size of the market. Pilkington PLC continued to serve the NZ market with imports of float glass from plants elsewhere, including Australia. 
clear float glass in NZ by firms from China, Indonesia and Thailand. The application was lodged by Australian authorities on behalf of Pilkington Australia Ltd. (PAL), the Australian subsidiary of Pilkington PLC, claiming material injury resulted to PAL in the NZ market.

This is an example of third-party antidumping (TPAD) and raises the interesting question of why a country would permit an $\mathrm{AD}$ action to be brought in its territory on behalf of foreign firms. The basic economics of dumping suggests that it is almost invariably in the national interest of the importing country and the rationale for $\mathrm{AD}$ is that policy-makers weight the interests of domestic producers more heavily than those of domestic consumers. ${ }^{3}$ Hence TPAD is a bit of a puzzle: with no domestic industry interests at all, why inflict damage on domestic consumers?

One obvious answer might be 'reciprocity': yes, NZ loses from Australian TPAD actions but it gains from TPAD actions brought in Australia on behalf of NZ firms. This is possible but, in this particular instance, NZ has never brought a TPAD case in Australia while four have been brought by Australia in NZ in the 1990s.

This paper suggests another explanation for allowing TPAD. In a setting where firms can establish international subsidiaries, TPAD can enhance the efficient international location of production. One could then justify it on standard economic welfare grounds both from the perspective of the joint welfare of the importing country and the complainant and even, as we show, from the welfare perspective of the importing country alone, albeit in some very special circumstances.

The purpose of this paper, however, is not to suggest that TPAD is wise policy. Indeed, the circumstances we describe below in which the importing country alone gains from TPAD are very particular. Furthermore, the case for TPAD based on the joint welfare of the importing country and the complainant is a second-best case: the circumstances in which joint welfare is raised by TPAD are circumstances in which the abolition of AD would be even better still.

The remainder of the paper is organised as follows. In the next section we discuss in a little more detail the experience of NZ with TPAD and the legal context in which it operates. Section 3 outlines our argument and sets up a model to demonstrate our arguments. Section 4 then considers a practical caveat in the Australia-NZ case and a final section summarises and concludes.

\section{Some background}

The legal background for TPAD arises in the GATT agreement, Article VI: 6(b) of which states that, "[t]he contracting parties may... permit a contracting party to levy an anti-dumping or countervailing duty on the importation of any product...which causes or threatens material injury to an industry in the territory of another contracting party exporting the product concerned to the territory of the importing contracting party" (italics added. See GATT, 1947.) Furthermore, Part 1: Article 14 of the 1994 Agreement on Implementation of Article VI (Antidumping) of the GATT entitled Anti-Dumping Action on Behalf of a Third Country addresses TPAD directly and stresses that, "[t]he decision whether or not to proceed with a case shall rest with the importing country" (see WTO, 1994.)

These enabling treaties then find their way into the relevant law and trade agreements of a number of GATT signatory countries, of course. So Title 19: Chapter 4: Subtitle iv: Part iv: Sec. $1677 \mathrm{k}$ of the US Code, for instance (see US Code Title 19), outlines US TPAD procedures. It is

\footnotetext{
${ }^{3}$ The one generally accepted exception to this is the case of predatory dumping which is not an issue here.
} 
significant that this section was enacted as part of the Omnibus Trade and Competitiveness Act of 1988 and so its sole concern is with procedures for US firms to initiate TPAD actions in other countries, not the facilitation of such actions in the US. The North American Free Trade Agreement (NAFTA) also covers TPAD by affirming, in Article 317, the signatory parties' commitment to $\S .14$ of the 1994 GATT Agreement on Implementation of Article VI.

In the New Zealand case, $\S 18$ of the Dumping and Countervailing Duties Act 1988 allows that NZ's AD law can be applied on behalf of foreign complainant firms just as if they were NZ firms (and there is nothing to specify the nature of 'material injury' any differently for such firms.) Furthermore, Article 15:8 of the Australia New Zealand Closer Economic Relations Trade Agreement (ANZCERTA (or just CER)) states the following: "[i]f a Member State. . is of the opinion that goods imported into the territory of the other Member State from outside the Area are being dumped and that this dumping is causing ...or threatening to cause material injury to an industry located in the first Member State, the other Member State shall, at the written request of the first Member State examine the possibility of taking action, consistent with its international obligations, to prevent material injury" (my italics. See Australian Department of Foreign Affairs, 1995).

One argument that has been made for $\mathrm{TPAD}^{4}$ is that it can be used to offset possible intermediate good problems: a NZ firm could get access to cheap, dumped, imported inputs and thereby have an 'unfair' advantage over an Australian rival in the final product market. This is addressed explicitly in Article 14 of the CER, which deals with intermediate goods problems: where the Member States policies' enable producers in one country to obtain intermediate goods "at lower prices or more favourable terms" than producers in the other. Section 4 of that Article covers remedies the Parties may seek and subsection (d) allows for, "initiation by the other Member State of anti-dumping or countervailing action in respect of goods imported from third countries in so far as this action would be consistent with other international obligations" (italics added.)

Since 1990 there have been four cases of TPAD brought in NZ, all on behalf of Australian firms, and I can find no evidence of any other TPAD initiations world-wide. ${ }^{5}$ Only one of these four cases has involved an intermediate good. Furthermore, a case brought for reasons of the "intermediate goods problem" would presumably be brought on behalf of the final-good producer, but $\mathrm{AD}$ cases require that material injury (or its threat) be demonstrated by producers of "like goods" to the allegedly dumped good, so it is not clear how such a case could be argued under AD law.

None of the four NZ cases has led to the imposition of AD duties and the reason may lie in the CER requirement that any such actions are consistent with the countries' GATT obligations. Article 14.4 of the GATT Agreement on Anti-Dumping notes that if a case is taken against another WTO member it must then be approved by the WTO Council for Trade in Goods (CTG). As the Council operates on a consensus basis, it could generally be vetoed by the dumping country and, perhaps for this reason, NZ has never taken a TPAD case to the Council.

\footnotetext{
${ }^{4}$ I am grateful to Peter Lloyd for drawing this to my attention.

5 " [I]n 1993... an application [was received] from a New Zealand industry... for an investigation into alleged dumping. . of goods into Australia which were claimed to be injuring the New Zealand industry. The application was referred to the Australian authorities but was subsequently withdrawn and replaced by an amended application in 1994. The amended application was also referred to the Australian authorities, but was also subsequently withdrawn. In neither case, therefore, was an investigation initiated." Correspondence from Martin Garcia, Ministry of Economic Development, Wellington NZ.
} 
The first case brought in $\mathrm{NZ}^{6}$ was in 1992 and concerned plaster of Paris bandages from Germany. The Ministry of Commerce (now Ministry for Economic Development) investigation concluded that dumping of the product in the NZ market had occurred, that it had not caused material injury to the Australian complainant but that it did constitute a threat of material injury. Accordingly, their recommendation to the relevant Minister was that the possibility of TPAD duties should be investigated. However, the exporter responded by increasing their price to non-dumping levels and no further action was taken.

The next case brought in NZ is one to which we have already referred: a case brought by Pilkington Australasia Ltd. in 1997 against clear float glass from Thailand, China and Indonesia being dumped in NZ. The investigation in this case found dumping and actual material injury to PAL and again recommended to the Minister that AD duties be considered. The Minister dropped Indonesia from the investigation on the grounds that the volume of dumped exports was insignificant, but decided (with the support of the Australian government) to pursue the possibility of levying AD duties on China and Thailand. Consultations were entered into with both countries and Thailand made it clear that they would block any consensus in the WTO's CTG to authorise AD duties. The Minister decided not to approach the CTG for approval for such TPAD duties and so not to impose any duties in this case.

In 1999 another TPAD investigation was commenced at the instigation of the Australian government on behalf of Merck Sharp and Dohme Australia Pty Ltd alleging the dumping in NZ of ACE inhibitors (a pharmaceutical) from Germany and Switzerland. And in 2000 a further TPAD investigation was commenced at the instigation of the Australian government on behalf of Amoco Chemicals Pty Ltd, an Australian firm, alleging the dumping in NZ of primary carpet backing fabric from Saudi Arabia - a preliminary report found that dumping had occurred but no evidence of damage or threat of damage to the Australian industry was determined. Both of these investigations were terminated due to the withdrawal of the respective applications by the Australian producer in question. ${ }^{7}$

To summarise, then, while a number of TPAD actions have been brought they have not resulted in any $\mathrm{AD}$ duties. Nevertheless, the fact that they were brought at all indicates that the complainants, at least, either anticipated some success (and, in the plaster of Paris case, achieved it) or brought them for harassment value. ${ }^{8}$

In the model that follows we assume that if TPAD actions are brought they will be successful where dumping actually occurs, but it should be borne in mind that the practical experience with TPAD has indicated that success is much less automatic! Furthermore, experience with TPAD, at least in Australasia, has been that it is not invoked for intermediate goods (the exception being the carpet backing case but the complainant therein was an Australian producer of carpet backing, not carpets.) One further wrinkle in the following model that is at odds with the reality of TPAD: we assume that the only relevant damage to the complainant firm is that which occurs in the importing country; in reality, the damage assessment in CER TPAD cases considers the impact of dumping in, say, NZ on the performance of a complainant in the entire Australia-NZ market. In the context of our model these are the same thing.

\footnotetext{
${ }^{6}$ See NZ Ministry of Economic Development for details on each of these cases.

${ }^{7}$ As a participant at the 2004 Nottingham Conference noted, the threat of CTG veto would not have applied in this case, as Saudi Arabia is not a WTO member.

${ }^{8}$ See Prusa (1992) for discussion of the harassment value of AD actions.
} 


\section{The argument and a model}

We first outline the basic argument we shall make here. Suppose, for concreteness, that an Australian firm and, say, a Thai firm could serve NZ either by exports or by establishing a subsidiary in NZ. In the absence of NZ TPAD suppose the equilibrium is such that the Australian firm establishes a subsidiary in NZ but the Thai firm does not. This enables the Australian firm to use NZ's regular AD law against the Thai firm and will tend to give high operating profits for the Australian firm in NZ but also means incurring the fixed costs of establishing a subsidiary. Allowing TPAD then enables the Australian firm to shut down its subsidiary (saving these fixed costs) and serve NZ from Australia, but to maintain high profits in NZ as the Thai firm must keep its prices high in NZ to avoid a TPAD case. From the joint perspective of Australia and NZ, then, if the subsidiary was an inefficient decision to start with (driven by a desire to pre-empt the Thai firm or to exploit AD rules in NZ) then its closure can represent a welfare improvement. Furthermore, it is also possible that NZ welfare alone could increase: if the NZ market is sufficiently small that a low-cost supplier can effectively capture the entire market then the establishment of a subsidiary in NZ can lead to monopoly prices. When the subsidiary is closed duopoly competition is restored and prices can fall. We now turn to a formal model to demonstrate these results.

Suppose we have three countries, $A, B$ and $C$. There is some good, $x$, which is consumed in all three countries but, initially, produced only in $A$ and $C$. So $A$ takes the role of Australia in our earlier discussion of the NZ cases, $B$ is New Zealand and $C$ represents Thailand. The single producer in each of $A$ and $C$ can serve the market in $B$ either through exports from their respective home countries or, potentially, by establishing a plant in $B$ at $\operatorname{cost} F_{j}, j=A, C$. So in each case below we have four configurations to consider: neither firm establishes a subsidiary in $B$, only $A$ 's firm does, only $C$ 's firm does or both firms do. We assume the following three-stage timing: the firm from country $A$ first decides whether or not to establish a subsidiary in $B$, the firm from country $C$ then decides whether or not to establish a subsidiary in $B$ and finally the firms then play Cournot simultaneously in all markets.

The constant marginal cost of production for each firm in any plant is $c_{i}=c, i=\mathrm{A}, \mathrm{C}$ and, as our focus is on $A$ and $B$, the firm in $A$ does not sell into country $C$. The per-unit cost of shipping from $j=A, C$ to $B$ is given by $t_{j}$ where $t_{A}<t_{C}$ and an exporter from $j$ also incurs a fixed cost of $M_{j}$ which represents the cost of establishing the export market. As firm $C$ 's market is largely irrelevant throughout this analysis we suppose its price is fixed at $p$. (Inverse) demand in country $i=A, B$ is given by $p^{i}=\alpha^{i}-\beta Q^{i}$ where $Q^{i} \equiv q_{A}^{i}+q_{C}^{i}, q_{j}^{i}$ denotes sales from country $j$ 's firm in country $i, j=\mathrm{A}, \mathrm{C}$ and $B$ is the smallest market: $\alpha^{B}<\alpha^{A}$. Generally, subscripts denote country of origin, superscripts country of operation. In country $B$, sales from either $A$ or $C$ could be due to exports from the home country or could be made from a local subsidiary in $B$.

As all competition is Cournot so, if a firm with effective $M C=c_{i}$ (i.e., including any transport costs) and one with $M C=c_{j}$ compete in market $X$, then, in equilibrium,

$$
\begin{aligned}
& q_{i}^{x}=\frac{1}{3 \beta}\left(\alpha^{x}-2 c_{i}+c_{j}\right) Q^{x}=\frac{1}{3 \beta}\left(2 \alpha^{x}-\left(c_{i}+c_{j}\right)\right) p^{x}=\frac{1}{3}\left(\alpha^{x}+\left(c_{i}+c_{j}\right)\right) \\
& \pi_{i}^{X}=\frac{1}{9 \beta}\left(\alpha^{x}-2 c_{i}+c_{j}\right)^{2} \text { and } C S^{x}=\frac{1}{18 \beta}\left(2 \alpha^{x}-\left(c_{i}+c_{j}\right)\right)^{2}
\end{aligned}
$$

all for $i, j=A, C i \neq j$, in self-explanatory notation (except that $\pi_{i}^{X}$ denotes operating profits of firm $i$ in country $\mathrm{X}$ excluding any fixed costs.) As our interest is in dumping, we suppose that the 


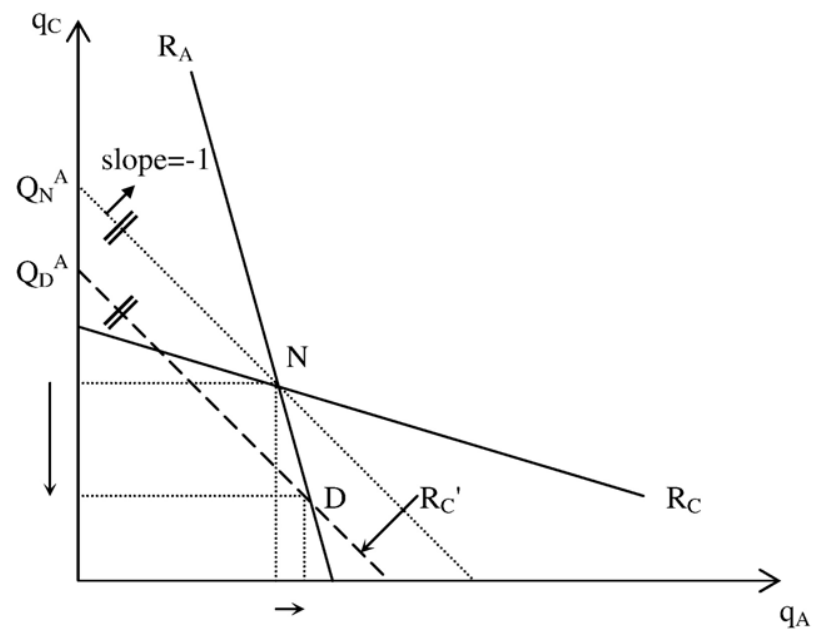

Fig. 1. AD in Cournot.

price in $C$ is greater than the price that would prevail in $A$ if served from $A$ and $C .{ }^{9}$ That is, we suppose throughout that $\underline{p}>\frac{1}{3}\left(\alpha^{A}+2 c+t C\right)$.

In this Cournot setting we capture the effect of $\mathrm{AD}$ as follows. If, say, the firm from country $C$ is dumping in $A$ (i.e., $p_{C}^{A}<p$ ) then the effect of an $\mathrm{AD}$ action is that $C$ must set its sales in $A$ such that the total quantity sold in $A$, including firm $A$ 's optimal output, is such that $p^{A}=p$. Diagrammatically, if the firms' initial reaction functions are $R_{A}$ and $R_{C}$, as shown in Fig. 1 , yielding a Nash equilibrium of $\mathrm{N}$ and total sales in $A$ of $Q_{N}{ }^{A}$, then an $\mathrm{AD}$ action transforms $C$ 's reaction function into $R_{C}{ }^{\prime}$ yielding an equilibrium at $D$ and total sales in $A$ of $Q_{D}^{A}$, where $\alpha^{A}-\beta Q_{D}^{A}=\underline{p}$.

Note that this approach means that an AD action is always beneficial for the complainant and harmful for the dumper - there is no facilitating aspect to the AD procedure, in contrast to some of the literature.

\subsection{No TPAD}

\subsubsection{No subsidiaries}

If neither $A$ 's firm nor $C$ ' $S$ firm establishes a subsidiary in $B$ then $B$ is served by exports and $C$ sells into $A$ directly from $C$. In $B$ 's market, then, $c_{A}=c+t_{A}$ and $c_{C}=c+t_{C}$ so, in the absence of any $\mathrm{AD}$ actions, we can calculate out the variables of interest from $(*) .{ }^{10} \mathrm{We}$ suppose throughout this section that all countries have non-discriminatory AD policies in place. So in $A$ 's market we have sales from $A$ 's firm at marginal $\cos c_{A}=c$ and sales from $C$ 's firm at marginal cost $c_{C}=c+t_{C}$. Cournot competition between these two would lead to a price that is less than $p$; thus an $\mathrm{AD}$ action brought by $A$ 's firm will raise the price to $p$ and we can calculate equilibrium profits for each firm, as well as consumer surpluses and welfare levels in $A$ and $B$.

\footnotetext{
${ }^{9}$ For simplicity we assume that the relevant domestic price of an import good for AD purposes is the c.i.f. price; that is, we do not look at the price net of transport costs.

${ }^{10}$ The algebra for each of these cases is provided in an Appendix available from the author on request.
} 


\subsubsection{A alone establishes a subsidiary in $B$}

Now things are unchanged in country $A$, so values of variables in country $A$ are as in Section 3.1.1. But in country $B$ the firm from $A$ serves the market at a $M C$ of $c_{A}=c$. Because $B$ 's market is so small, we assume that, while the firm from country $C$ is profitable competing in $B$ against a rival exporting from $A$, it would make losses in $B$ if it were to attempt to compete, subject to an $\mathrm{AD}$ action, against a subsidiary of $A$ 's. That is, we suppose that $\pi_{C}^{B}\left(c_{A}, c_{C}\right)-M_{C}=\pi_{C}^{B}(c$, $\left.c+t_{C}\right)-M_{C}<0$. Accordingly, $A$ makes monopoly profits in $B$ and, again, we can calculate equilibrium profits for each firm, consumer surpluses in $A$ and $B$ and welfare levels in $A$ and $B$.

\subsection{3. $C$ alone establishes a subsidiary in $B$}

Now in country $B$ the firm from $C$ serves the market at a $M C$ of $c_{A}=c$ and, symmetrically to the previous case, we assume that the firm from country $A$ would also make losses in $B$ if it were to attempt to compete, subject to an $\mathrm{AD}$ action, against a subsidiary of $C$ 's. Accordingly, $C$ makes monopoly profits in $B$.

As far as the market in $A$ is concerned, however, firm $C$ has two choices: it can serve it from home, facing an $\mathrm{AD}$ action as in the previous cases, or it can serve it more cheaply by exporting from its subsidiary in $B$ (and incurring per-unit transport costs $t_{A}<t_{C}$ ). In this latter case, however, it may still face an $\mathrm{AD}$ action in $A$. We consider this case first. The "naïve" optimal price to set in $B$ for $C$ 's monopolist subsidiary is $p^{B}=\frac{1}{2}\left(\alpha^{B}+c\right)$ and if $C$ exports to $A$ from $B$ Cournot competition in $A$ will yield $p^{A}=\frac{1}{3}\left(\alpha^{A}+2 c+t_{A}\right)$. So we will observe an AD action by $A$ against $C$ 's subsidiary in $B$ if $3 \alpha^{B}>2 \alpha^{A}+c+2 t_{A}$ which we henceforth assume is the case. We can then solve out for profits. The other alternative is that $C$ simply reaps monopoly profits in $B$ and serves $A$ 's market, subject to an $\mathrm{AD}$ action, from $C$. In this case its profits in $B$ will simply be $\Pi_{C}^{B}=\frac{1}{4 \beta}\left(\alpha^{B}-c\right)^{2}-F_{C}$ and in $A \Pi_{C}^{A}=\frac{1}{\beta}\left(\alpha^{A}+c-2 \underline{p}\right)\left(\underline{p}-\left(c+t_{C}\right)\right)$. Thus, for the firm to serve $A$ 's market from its subsidiary in $B$, we can derive an inequality based on comparing these profit levels — an inequality that we assume henceforth holds.

\subsubsection{Both firms establish a subsidiary in $B$}

It might seem that we could never observe both firms with subsidiaries in $B$ given that when one sets up and the other competes through exports the latter's profits are less than the marketing cost of exporting. However, if both do establish then they each serve $B$ 's market at a marginal cost of only $c$ which yields lower prices but higher profits so it is possible that operating profits in $B$ now exceed the fixed cost of establishing a subsidiary.

The problem facing $A$ 's firm now is straightforward. The problem facing $C$ 's firm, however, is again complicated by the choice of source country from which to serve $A$ 's market. Suppose, first, that it serves $A$ from its lower transport-cost source: its subsidiary in $B$. Solving this yields $p^{A}>p^{B}$ so there is no dumping issue. The other alternative for $C$ 's firm, however, is to serve $A$ 's market from $C$ and again we can derive an inequality based on the firm's comparative profit levels such that serving $A$ from $B$ is an equilibrium choice.

\subsubsection{Equilibrium with no TPAD}

We summarise this case, then, as follows.

(i) When neither firm establishes a subsidiary in $B$ they each compete there (incurring marketing costs) with marginal costs equal to production costs plus their respective transport costs. In $A$ 's market $C$ 's firm finds itself subject to an AD action and so its output is reduced (while $A$ 's expands) until the price there equals that in country $C$. 
(ii) When $A$ alone establishes a subsidiary in $B$ it incurs some fixed cost to do so but then saves its marketing costs and lowers its marginal cost in that market. It lowers it sufficiently, in fact, that $C$ 's firm cannot compete at its higher effective marginal cost so $A$ 's firm is a monopolist in $B$. In $A$ things are exactly the same as in case (i).

(iii) If only $C$ were to establish a subsidiary in $B$ then it would become the local monopolist. This does not leave things unchanged in $A$, however: when $C$ 's firm attempts to serve the market in $A$ from its subsidiary in $B$ (which is lower-cost than its plant at home in $C$, due to lower transport costs between $A$ and $B$ than between $A$ and $C$ ) it will face an AD action. So this affects its choice of quantity (and hence price) in $B$ and thus in $A$.

(iv) Finally, if both firms set up subsidiaries in $B$ then each has lower marginal costs there (production costs only) and $B$ will now not face an $\mathrm{AD}$ action from $A$ if it attempts to serve $A$ 's market from $B$, its lowest-cost source, as the price in $B$ is lower than that in $A$.

We assume parameter values are such that case (ii) prevails: $A$ chooses to establish a subsidiary in $B$ and $C$ does not. $C$ then serves only the market in $A$ and $A$ serves each market from on site. Denoting firm $i$ 's profits in case $j$ as $\Pi_{i}^{j}$, in addition to the assumptions already made, then, necessary conditions for this to hold are that $\Pi_{A}^{2}>\Pi_{A}^{3}$ if $\Pi_{C}^{3}>\Pi_{C}^{1}$ and $\Pi_{A}^{2}>\Pi_{A}^{1}$ if $\Pi_{C}^{1}>\Pi_{C}^{3}$, which ensures that $A$ prefers a subsidiary to no subsidiary, and that $\Pi_{C}^{2}>\Pi_{C}^{4}$ which ensures that $C$ 's best response to $A$ 's subsidiary is to not establish a subsidiary itself.

\subsection{TPAD permitted between $A$ and $B$}

We now suppose that countries $A$ and $B$ sign a reciprocal TPAD agreement. The consequences of this for our outcomes above will be zero in every case but the first as that is the only case in which country $C$ serves country $B$ through exports.

\subsubsection{No subsidiaries}

The effect of allowing TPAD here is that the firm from country $A$ can now force $C$ ' $s$ firm to price in $B$ as it does in $C$. This clearly benefits $A$ 's firm while harming $C$ 's firm. The effect of allowing TPAD, ${ }^{11}$ then, is simply to make the establishment of a subsidiary by $A$ less attractive — with TPAD in place it can raise the price charged in $B$ without incurring the costs of establishing a subsidiary in $A$. If it makes it so attractive that $A$ chooses not to establish a subsidiary in $B^{12}$ then, while this is good for welfare in A, as the firm's profits rise if this is an attractive strategy, it turns out that it can also be good for B: when $A$ does not establish a subsidiary $B$ 's consumers no longer face a monopoly but, rather, a duopoly. This duopoly is not as competitive as they might like, as $C$ is subject to a TPAD action but, nevertheless, it may well be better than a monopolist (only may be better, because the monopolist is at least low-cost, serving the market at a marginal cost of $c$.)

This outcome - the introduction of TPAD leading A's firm to shut down its subsidiary - is more likely the greater are $A$ 's fixed costs of establishing a subsidiary relative to its marketing costs $\left(F_{A}\right.$ versus $\left.M_{A}\right)$ and the lower is the price in $B$ in the absence of TPAD - the TPAD action then raises $A$ 's profits in $B$ more significantly. This also requires that establishing a subsidiary is

\footnotetext{
${ }^{11}$ Again, see the Appendix, available on request, for the algebra of this case.

12 As C's profits in case (i) (no subsidiaries) are reduced, so the introduction of TPAD can also change C's behaviour, making a subsidiary more attractive. If it makes it more attractive than having none then this may induce A to maintain its subsidiary as a pre-emptive move, leaving no observed effect of TPAD.
} 
Table 1

Simulation parameter values

\begin{tabular}{ll}
\hline Variable & Value \\
\hline$\alpha^{A}$ & 25 \\
$\alpha^{B}$ & Free \\
$\beta$ & 2 \\
$c$ & 2 \\
$t_{A}$ & 5 \\
$t_{C}$ & Free \\
$p_{C}$ & 13 \\
$F_{A}$ & 60 \\
$F_{C}$ & 69 \\
$M_{A}$ & 15 \\
$M_{C}$ & 12 \\
\hline
\end{tabular}

not attractive to $C$ which will be the case if their fixed costs are substantial, relative to the difference in transport costs $t_{C}$ and $t_{A}$, and if an $\mathrm{AD}$ action taken by $A$ against exports from $B$ 's subsidiary is costly.

\subsection{A numerical simulation}

As the algebraic comparisons required above are too messy to yield much insight, we have simulated a simple numerical example to illustrate that the case we discuss above is at least possible. We assume the parameter values shown in Table 1 and our results are shown in Fig. 2.

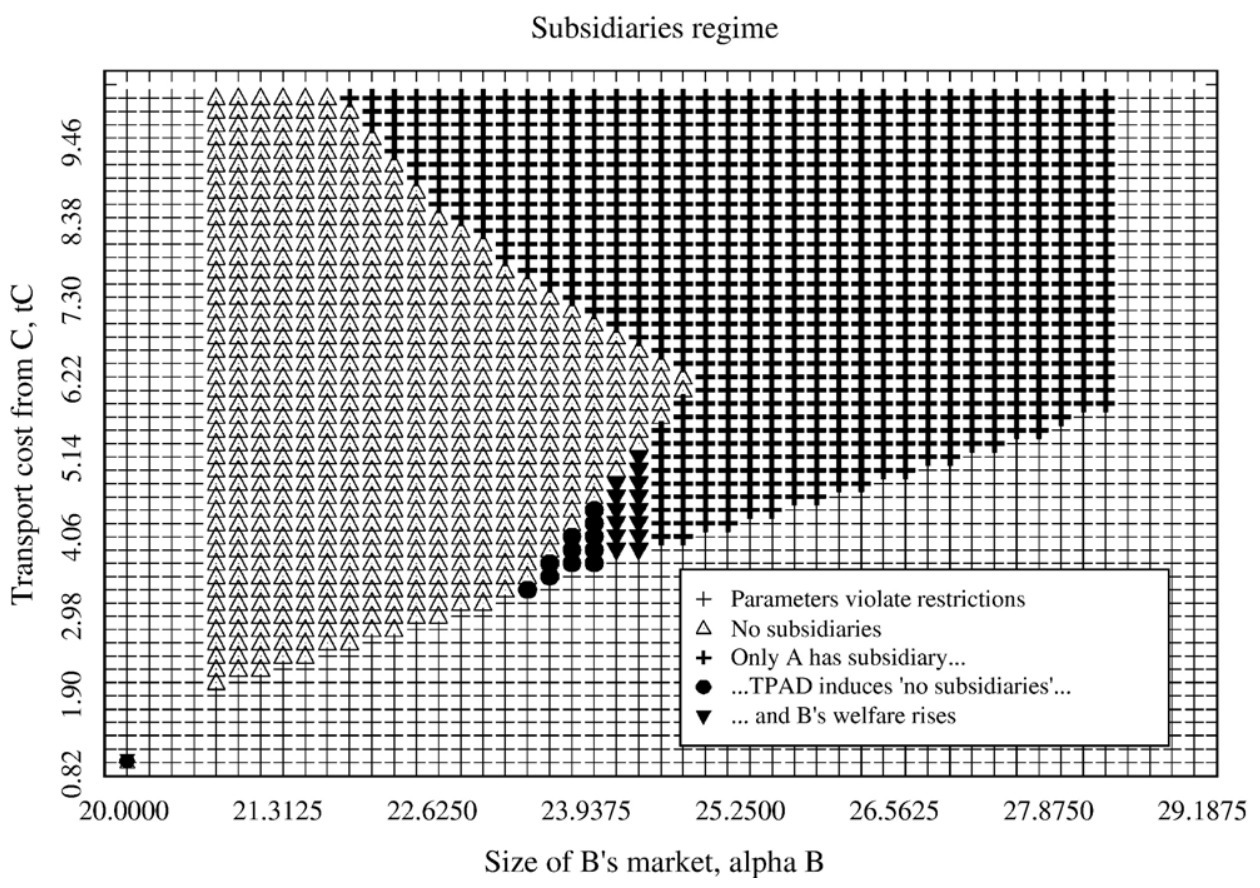

Fig. 2. Simulation results. 
We have conducted the search over parameter values to illustrate the range for which our restrictions are binding. So, absent $\mathrm{AD}$ actions, $\alpha^{B}$ can be too low for dumping to occur from $B$ to $A$ when only $C$ has a subsidiary in $\mathrm{B} ; t_{C}$ can be too low so there would be no dumping for sales from $C$ into $\mathrm{A}$; and either $t_{C}$ or $\alpha^{B}$ can be too high so that either firm from $A$ or $C$ can compete from home in $B$ with a rival's subsidiary, so such a single subsidiary would not be a monopolist. In any of these cases we have the peripheral outcomes shown in Fig. 2 where the restrictions are violated.

For the remaining parameter values, when $\alpha^{B}$ is low we tend to get an outcome with no subsidiaries in $B$ for either firm. As $\alpha^{B}$ increases (and, generally, as $t_{C}$ increases for given $\alpha^{B}$ ) however, we switch to a regime wherein $A$ prefers to establish a subsidiary in $C$. This is because as $B$ 's market grows the attractiveness of being a monopolist there increases (and the effect of rising $t_{C}$ is generally to make a subsidiary in $B$ more attractive for $C$, for serving the market in $A$, and therefore a pre-emptive subsidiary in $B$ more attractive for $A$.)

Now suppose we allow TPAD. A small subset of the cases in which otherwise only $A$ would establish a subsidiary - those with dark symbols - are such that the introduction of TPAD leads $A$ to prefer having no subsidiary in $B$. The main savings for the firm in $A$ are the fixed costs associated with serving $B$ through exports rather than a subsidiary. The price in $B$ falls with this, note, and while joint welfare of $A$ and $B$ rises, we have also identified in Fig. 2 an even smaller subset of parameter values in which $B$ 's welfare alone rises.

So, how likely is all this? To the extent that our simulations tell us anything, they suggest that a small but significant number of cases exists in which TPAD might induce a change of behaviour by a DFI source country (Australia, in our earlier example) and in a sizeable number of those cases this can be beneficial to the DFI host country (NZ) ${ }^{13}$. Certainly if we restrict our attention to those configurations which satisfy our starting conditions - in Fig. 2 only those cases in which $A$ has a subsidiary in the absence of TPAD - then our results are not 'unlikely'. Different parameter values will give different results, of course, but we can see that the outcomes we have discussed are possibilities, at least.

\section{A fly in the ointment}

One practical feature of the Australia-NZ situation that we have not so far considered is that, in 1990, the two countries agreed to abolish AD between them (leaving predation to be dealt with, appropriately, by competition law.) This will change our results derived earlier, with and without TPAD, only when $C$ alone ${ }^{14}$ establishes a subsidiary in $B$, as it can now serve the market in $A$ from that subsidiary with no fear of an AD action.

\subsection{C alone establishes a subsidiary in B}

In the case where $C$ alone establishes a subsidiary in $B$, it now obtains monopoly profits there and, in $A$, all outcomes are described by a regular Cournot equilibrium with $C$ 's marginal costs being $c+t_{A}$ and $A$ 's being just $c .^{15}$

The only possible effect abolishing 'internal' AD can have for our analysis of TPAD is to make the establishment of a subsidiary by $C$ more attractive. So either it has no consequences for

\footnotetext{
13 Of course, the parameters were chosen, recall, so that a subsidiary in $B$ would be a monopolist.

${ }^{14}$ When both establish subsidiaries the price in $B$ will be less than that in $A$ so AD will be irrelevant.

15 See Appendix, available on request, for the algebraic results in this case.
} 
our earlier results (if the increased profitability from establishing a subsidiary is small) or it will tempt $C$ to establish a subsidiary. In the latter case the no-TPAD case has a monopolist in $B-$ either $A$ 's subsidiary or $B$ 's - and TPAD is irrelevant: there are no sales from $C$ into $B$. In a sense, then, the absence of internal AD makes our earlier, highly improbable result (that TPAD can raise joint welfare and even the importing country's welfare) even less likely.

In our numerical examples it turns out, however, that this wrinkle makes no difference: in those cases in which $A$ would prefer to remove its subsidiary when TPAD is introduced, it still wishes to do so in the absence of $A-B$ AD.

\section{Summary and conclusion}

After a review of TPAD legislation and some Australia-New Zealand cases, this paper has presented a stylised model to illustrate the possibility that allowing TPAD could be welfareimproving from the joint perspective of two countries and even from the perspective of the importing country alone. Some numerical simulations were run to illustrate this case.

The central questions here, of course, are just how likely is this case and are there better policies than TPAD? On the former, the case in which the mutual welfare of $A$ and $B$ could be enhanced by TPAD does not seem too obscure - if $A$ sets up in $B$ primarily to establish a domestic presence to exploit $\mathrm{AD}$ rules (and there is certainly evidence that $\mathrm{AD}$ laws can affect firms' locational decisions - see Belderbos et al., 2004; Blonigen, 2002 and references therein, although this is evidence on AD-duty jumping, not exploitation) then TPAD, by undoing that, can be a useful policy. This reasoning makes it clear, however, that this argument for TPAD is very much a second-best argument and would be dominated by simply abolishing AD altogether (for all the reasons economists have advanced for years.) In such a case, $A$ 's incentive to set up inefficiently in $B$ in the first place would be removed. Furthermore, any possible benefits of TPAD in this setting must be weighed against the harmful aspects of TPAD (those of AD policy generally) when used in contexts where international relocation is not an issue.

How likely is it that TPAD can raise welfare in $B$ ? We have made no secret of the fact that the scenario we set up here is very special. For TPAD to improve welfare in the importing country it must be that it leads to a fall in prices. This is not the usual consequence of AD actions and only occurs here because of the special parameter assumptions we have made which ensure that any production facility in $B$ would operate as a monopolist. This is possible, of course, if there are substantial transport costs as in our simulations (so the local producer has a big cost advantage) and substantial marketing costs associated with exporting (so foreign competitors stay out, in anticipation of variable profits, in competition with the low-cost local producer, too small to cover these costs).

Three final conclusions follow. First, from a practical perspective there are institutional barriers to TPAD that make it effectively unworkable (namely, the requirement that GATT members get CTG approval) and so unlikely to be of serious concern. Second, from a theoretical perspective, our analysis does suggest that, undesirable though TPAD might generally be for an importing country, it is likely to be more attractive in a free trade area where one might more sensibly argue that policy is set from the welfare perspective of countries jointly. Third, it is worthwhile noting that the conduct of TPAD as we have described it here can be isomorphic to the operation of AD more generally as a region-wide policy, such as in the European Union. ${ }^{16}$ That is, the conduct of trade policy within the EU can resemble that of the analysis here - if an

\footnotetext{
${ }^{16} \mathrm{I}$ am grateful to a referee for this observation.
} 
$\mathrm{AD}$ action is brought to protect a French firm, say, from Chinese competition in the EU where most of the EU market is outside France then this is essentially TPAD as discussed here. In this respect our model is of more general application than might at first appear.

\section{Acknowledgements}

An earlier version of this paper was presented at the GEP conference on "100 years of AntiDumping" held at Nottingham in June 2004. I am extremely grateful to Martin Garcia, Bruce Cullen and Rory McLeod at the New Zealand Ministry of Economic Development and Stephen Harris at the New Zealand Ministry of Foreign Affairs and Trade, in Wellington, for their patient and extensive help on the details of NZ third party antidumping investigations. I am also grateful to Peter Lloyd for some discussion on this topic and to Tom Prusa, Rod Falvey, an anonymous referee and participants at the GEP Anti-Dumping Conference in Nottingham. All errors and opinions expressed in this paper are, of course, my own.

\section{References}

Australian Department of Foreign Affairs, 1995. Australia New Zealand Closer Economic Relations Trade Agreement 1983Australian Government Publishing Service, Canberra (http://www.dfat.gov.au/geo/new_zealand/anz_cer/ anzcerta1.pdf. Accessed 18/05/04).

Belderbos, R., Vandenbussche, H., Veugelers, R., 2004. Antidumping duties, undertakings, and foreign direct investment in the EU. European Economic Review 48, 429-453.

Blonigen, B., 2002. Tariff-jumping antidumping duties. Journal of International Economics 57, $31-49$.

GATT, 1947. The General Agreement on Tariffs and Trade (http://www.wto.org/english/docs_e/legal_e/gatt47_01_e.htm. Accessed 18/05/04).

National Business Review, 1991. "Pilkington's “outdated” glass plant to close.” 13 February 1991, Auckland, NZ.

NZ Ministry of Economic Development, assorted Reports and Summaries of Anti-dumping investigations, Wellington, NZ. Available at http:/www.med.govt.nz/ buslt/trade_rem/complete.html\#dump. Accessed 18/05/04.

Prusa, T., 1992. Why are so many anti-dumping petitions withdrawn? Journal of International Economics 33, 1-20.

US Code Title 19: Chapter 4: Subtitle iv: Part iv: Sec. 1677k. Available at Legal Information Institute, Cornell Law School, http://www4.law.cornell.edu/uscode/ 19/1677k.html. Accessed 18/05/04.

WTO, 1994. Agreement on Implementation of Article VI of the General Agreement on Tariffs and Trade 1994 (http:// www.wto.org/english/docs_e/ legal_e/19-adp_02_e.htm. Accessed 18/05/04). 